\title{
PENGARUH NILAI WETTABILITY TERHADAPA BUBBLE DEPARTURE DIAMETER DAN BUBBLE DEPARTURE FREQUENCY
}

\author{
BAMBANG JOKO SUROTO, ASWAD HI SAAD, LIU KIN MEN \\ Departemen Fisika Fakultas MIPA Universitas Padjadjaran, \\ Jl. Raya Bandung-Sumedang Km 21, Jatinangor 45363 \\ *email : bambang.s@phys.unpad.ac.id
}

\begin{abstract}
Abstrak. Studi tentang efek dari nilai wettability dari permukaan pada bubble departure diameter dan bubble departure frequency telah dilakukan dengan menggunakan air murni sebagai fluida kerja dan defaat subcooling $0 \mathrm{~K}$. Heat transfer block yang digunakan adalah dipoles tembaga/hidrofilik, dan superhydrophilic /TiO2. Hasil penelitian menunjukkan bubble departure diameter lienar dengan nilai besaran contact angle dan nilai bubble departure frequency semakin meningkat dengan menurunnya nilai contact angle hal ini sensuai dengan Model Frist dan bertentangan dengan Zubers model.
\end{abstract}

Kata kunci : Wettability, subcooling, super/hydrophilic, superhydrophilic, boiling

\begin{abstract}
The effect of varying surface wettabilitie bubble departure diameter dan bubble departure frequency has been examined and investigated. The experiments were performed using pure water as the working fluid and subcooling is $0 \mathrm{~K}$. The heat transfer block used were bare surface/hydrophilic (polished copper), and superhydrophilic/TiO2coated- on copper. The results showed that bubble departure frequency and bubble departure frequency strong correlated with contact angle and its match with existingmodel Frist and Zuber.
\end{abstract}

Keywords : Wettability, subcooling, super/hydrophilic, superhydrophilic, boiling

\author{
Nomenclature \\ $\mathrm{Ra}$ : arithmetic average roughness $(\mu \mathrm{m})$ \\ $\mathrm{Rz}$ : average roughness $(\mu \mathrm{m})$ ) \\ Tsat : saturated temperature $\left({ }^{\circ} \mathrm{C}\right)$ \\ $\theta$ : contact angle $\left(^{\circ}\right)$ \\ $\mathrm{r}$ : enhance surface area \\ tw : waiting time \\ $\mathrm{tg}$ : waiting time \\ $\mathrm{fb}$ : bubble departure frequency \\ Db: bubble departure diameter
}

\section{Pendahuluan}

Dalam dunia elektronik di mana hukum Moore memprediksi bahwa jumlah trasnsitors yang dapat ditempatkan pada IC ( Intregated Circuit) akan menjadi double setiap dua tahun dan transistor dalam jumlah yang sangat massiv (billion) akan meningkatkan perfroma dar IC tersebut. Sayangnya, hal itu juga mendapatkan sesuatu yang lain: panas dalam jumlah besar di mana equal dengan reaktor nuklir seperti yang digambarkan pada Gambar 1. Situasi yang lebih kritis dapat ditemukan di pusat data yang besar di mana power yang dikonsumsi untuk pendinginan 
sekarang sama dengan daya yang dikonsumsi oleh system itu sendiri. Miniaturisai dalam segala aspek teknologi dan berhubungan energy memang menuntut adanya pendingin super.

Sampai saat ini hampir semua pendinginan menggunakan udara dalam suhu kamar. Pendinginan dengan udara mempunyai prospek yang kurang baik di masa depan karena meningkatnya densitas power dan jauh lebih efisien dengan menggunakan berpendingin air. Ini saatnya era pendingin air comeback karena jumlah kalor yang bisa diserap persatuan massa dan waktu.
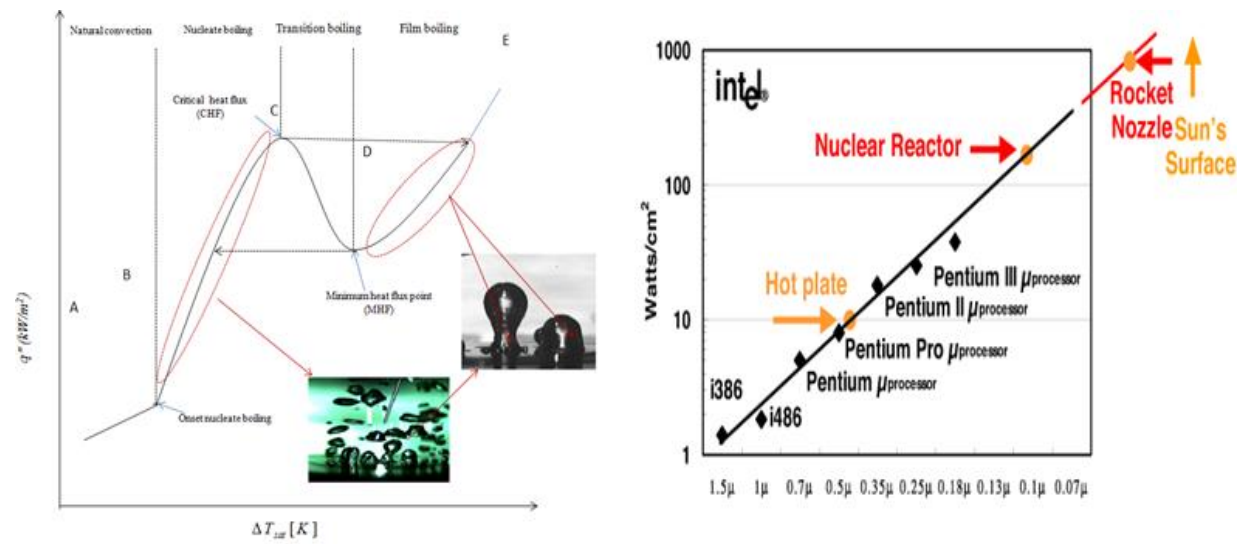

Gambar 1. Boiling curve dan heat flux unutk xetiap genenasi mikroprosesor

Didih (boiling) dalah salah satu fenomena perubahan fase disertai dengan gelembung. Ada dua mode boiling heat transfer dianataranya : flow dan pool boiling heat transfer. Keduanya dibedakan dengan adanya flow dari fluida kerja dan pool boiling heat trasnfer dicirikan oleh fluida yang statik dalam bentuk kolam (pool). Keduanya mempunya karakteristik yang sama, yaitu dipengaruhi oleh parameter-parameter seperti : situs nukleasi aktif $\left(N_{a}\right)$, bubble dimater $\left(V_{b}\right)$, frekuensi keberangkatan gelembung $\left(f_{b}\right)$ dan superheating $\left(\Delta T_{s a t}\right)$ (Tong dan Tang) [1].

Wettability atau keterbasahan adalah salah satu karaktersitic dari sifat permukaan selain kekasaran (roughness). Wettability yang diukur dengan contact angle (sudut kontak) dan menunjukan efek signifikan bahkan dominan terhadap performa boiling heat transfer (BHT). Wettability dengan sudut kontak $<90^{\circ}$ akan manaikan nilai critical heat flux $(\mathrm{CHF})$ sedangkan sudut kontak, $\mathrm{CA}>90^{\circ}$ akan mempromote bubble lebih awal dan menaikan heat transfer coefisient (HTC) pada flux panas rendah (Takata et al, 2006) ${ }^{2}$. Wettability juga mempengaruhi bentuk bubble dan dinamika ukuran bubble dan bubble departure frequency.

\section{Metode Penelitian}

Beberapa step eksperimen harus dilakukan agar tujuan penelitian ini tercapai. Desain dari appartus ekperimen kami seperti ditunjukan pada gambar 2. Vessel terdiri dari glass cilyder (2) dengan inner diameter sebesar $120 \mathrm{~mm}$ dan box-glass denagn dilapisis insulator(3). Heater (8) unutk memonitor dan menjaga temperature cairan(air murni). Temperature cairan di kontrol dengan heater (5) dan condenser(4). Pada saat bersamaan, temperature di record dengan menggunakan 
thermocouple sensor (6) dan pengkuruan dalam kondisi steady state. Selanjutnya, setelah semua sample dinstall, vessel kemudian di vaccum dengan pompa vaccum. Setelah kondisi vaccum tercapai maka air murni dimasukan sekaligus mengecek apakah terjadi kebocoroan dalam system apa tidak. Semua itu disebut proses degassing, proses deggasing selanjutnya liquid dipanaskan selama 30 menit.

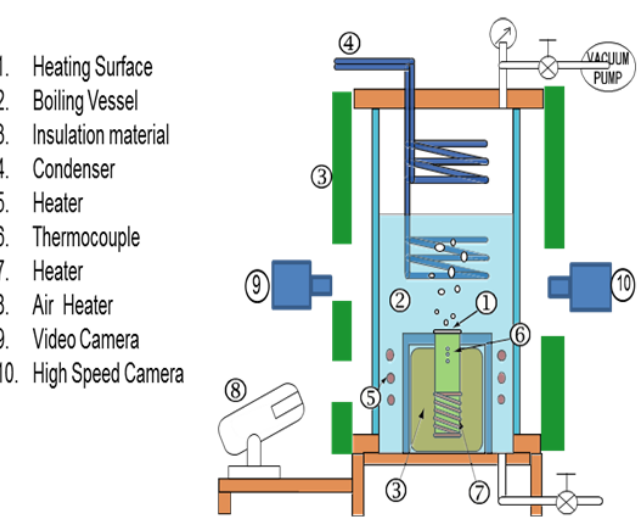

(a) Experimental apparatus

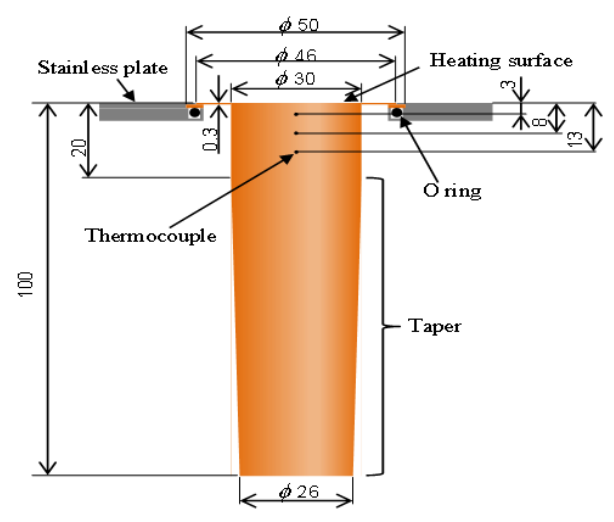

(b) Heater block

Gambar 2. (a) Skema dari eksperimen apparatus dan (b) heater block

Sedangkan sifat fisis atau morpologi dari sample uji ditunjukan oleh table 1. Dari table 1. dikeathui bahwa semakin kecil nilai contact angle maka semakin kasar atau menigkat nilai roughnes.

Tabel 1. Physical properties dari polished-copper dan $\mathrm{TiO} 2$

\begin{tabular}{lllll}
\hline Sample surface & $R_{\mathrm{a}}$ & $R z$ & $\begin{array}{l}\text { Contact angle } \\
(\theta)\end{array}$ & $\begin{array}{l}\text { Enhancement of } \\
\text { surface area }(r)\end{array}$ \\
\hline Polished copper & 0.007 & 0.045 & $66^{\circ}-70^{\circ}$ & 1.009 \\
\hline $\mathrm{TiO}_{2}$ & 0.568 & 5.564 & $\simeq 0^{\circ}$ & 2.077 \\
\hline
\end{tabular}

\section{Hasil dan Pembahasan}

Pada bagian ini kami akan menjelaskan dinamika gelembung, yaitu gelembung diameter keberangkatan, $D_{b}$, dan frekuensi gelembung keberangkatan, fb. Kami akan membahas dinamika gelembung dari tembaga- dipoles dan permukaan $\mathrm{TiO}_{2}$. diskusi akan fokus pada dua bahan karena sulitnya menentukan ukuran diameter gelembung keberangkatan pada permukaan hidrofobik. Gambar 3. menunjukkan keberangkatan frekuensi gelembung, fb, dari permukaan tembaga-dipoles $\left(\theta=66^{\circ}\right.$ $\left.-70^{\circ}\right)$ dan permukaan $\mathrm{TiO} 2\left(\theta \simeq 0^{\circ}\right)$. Pengukuran frekuensi keberangkatan gelembung menggunakan camera berkecapatan tinggi ( high speed camera). Dalam kasus ini, frekuensi gelembung keberangkatan dijelaskan dalam Persamaan (1) untuk permukaan sampel yang memiliki sudut kontak $0^{\circ}<\theta<90^{\circ}$. 
Frekuensi keberangkatan gelembung, fb:

$$
f_{b}=\frac{1}{\left(t_{w}+t_{g}\right)}
$$

Dimana $t_{w}$ dan $t_{g}$ adalah waktu tungu (waiting time) dan waktu tumbuh (time growth). Gambar 3. menunjukan bahwa permukaan $\mathrm{TiO}_{2}$ memiliki frekuensi keberangkatan gelembung lebih tinggi dari permukaan tembaga-dipoles. Model dari Phan et al. (2009) ${ }^{3}$ dan Fritz (1935) ${ }^{4}$ digunakan karena kedua model secara eksplisit menyertakan sudut kontak $(\theta)$. Menariknya, kedua model menunjukkan cukup kontras dan model Fritz (1935) yang sesuai dengan hasil eksperimen.

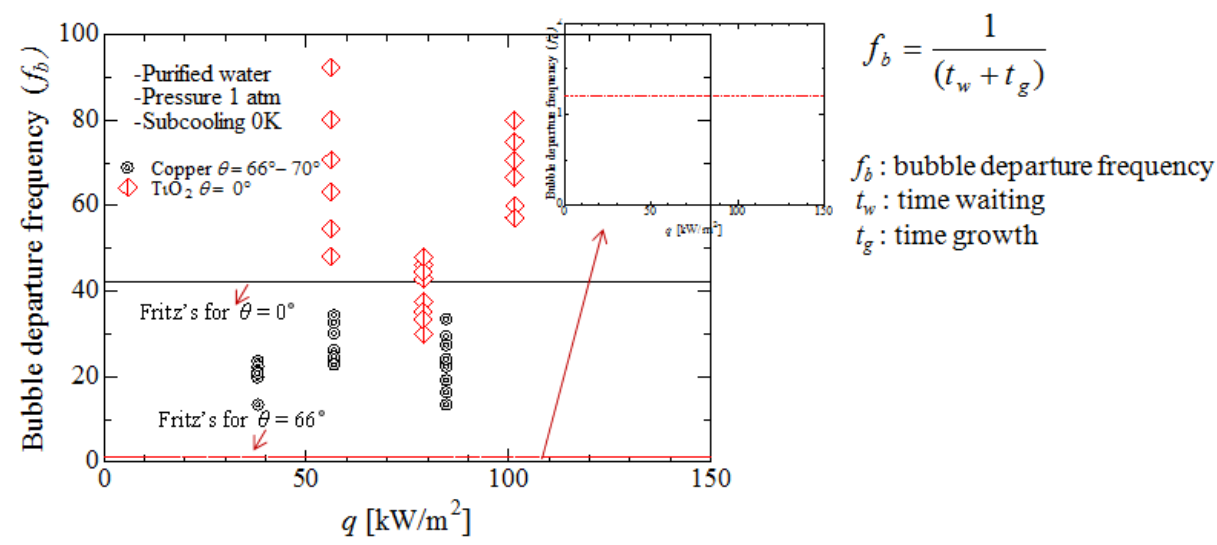

Gambar 3. Hasil eksperimen bubble departure frequency dari polished-copper and $\mathrm{TiO}_{2}$

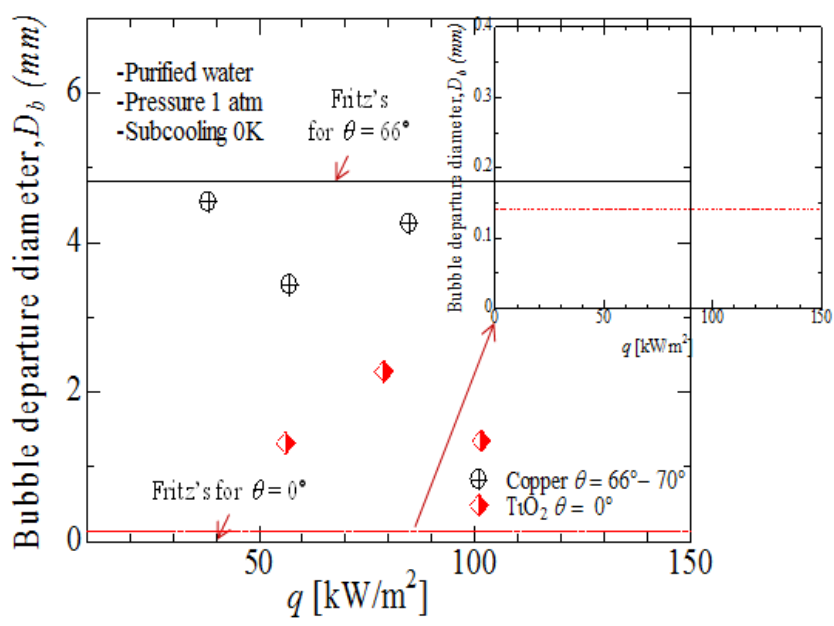

Zuber`s model :

$f_{b} D_{b}=0.59\left[\frac{\sigma g\left(\rho_{l}-\rho_{v}\right.}{\rho_{l}^{2}}\right]^{1 / 4}$

Gambar 4. Hasil eksperimen bubble departure diameter dari polished-copper and $\mathrm{TiO}_{2}$

Gambar 5 dan gambar 6. menunjukkan pertumbuhan gelembung pada tembagadipoles dan permukaan $\mathrm{TiO}_{2}$. Proses evolusi dari gelembung diamati dengan seksama dengan menggunakan high speed camera. Time growth ( waktu tumbuh) adalah waktu dimana bublle mulai muncul sampai terlepas 9 ditunjukan dengan 
adanya tanda anak panah mearh) dan waiting time ( waktu tunggu) adalah waktu yang dibutuhkan untuk munculnay bubble berkutnya.

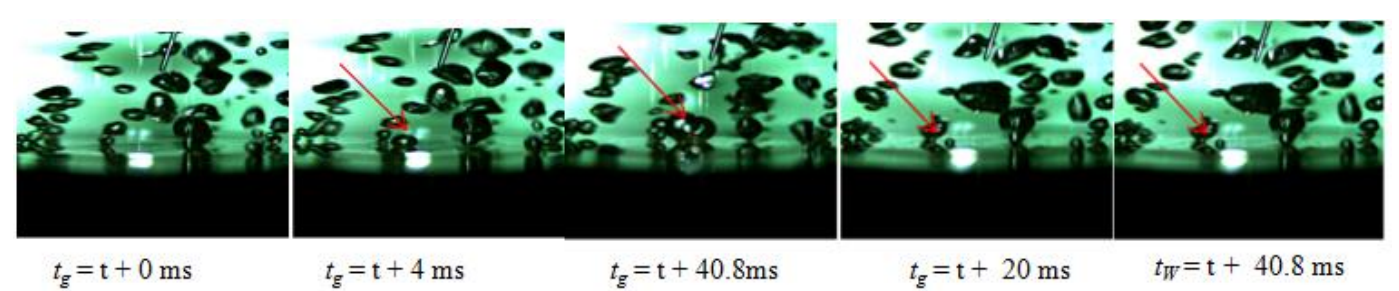

Gambar 5. Mekanisme Bubble growth dipermukaan hydrophilic (polished-copper)

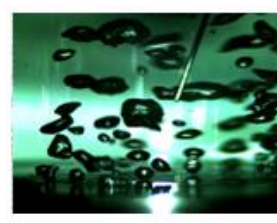

$t_{\mathrm{g}}=\mathrm{t}+0 \mathrm{~ms}$

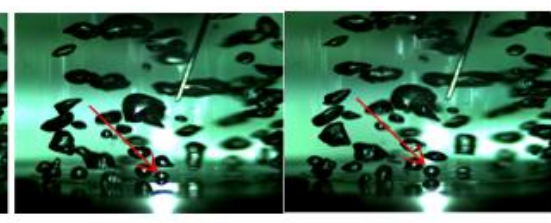

$t_{g}=\mathrm{t}+3.3 \mathrm{~ms}$

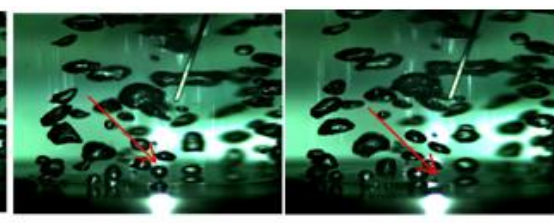

$t_{g}=\mathrm{t}+11.7 \mathrm{~ms}$
$t_{W}=\mathrm{t}+.7 \mathrm{~ms}$

Gambar 6. Mekanisme Bubble growth dipermukaan superhydrophilic $\left(\mathrm{TiO}_{2}\right)$

\section{Kesimpulan}

Wettability mempengaruhi bentuk geometri dari bubble departure. Frequency keberangakatan dari bubble dipengaruhi oleh bentuk bubble sedangkan bentuk bubble dipengaruhi oleh wettability maka dengan demikian wettability juga mempengaruhi secara langsung bubble departure frequency.

\section{Daftar Pustaka}

1. L.S. Tong and Y.S Tang, Boiling Heat Transfer and Two-Phase Flow, (1997) TAYLOR\& FANCOIS

2. Y. Takata, S. Hidaka, M. Masuda, T. Ito, Pool Boiling on a Superhydrophilic Surface, Int. J. Energy Res. Vol. 27 (2003) p. 111-119.

3. H. P. Phan, N. Caney, P. Marty, S. Colasson, J. Gavillet, Surface Wettability Control by Nanocoating: The Effects on Pool Boiling Heat Transfer and Nucleation Mechanism, International Journal of Heat and Mass Transfer Vol. 52 (2009) p. 5459-5471.

4. I. L. Pioro, W. Rohsenow, S. S. Doerffer, Nucleate pool-boiling heat transfer . I: review of parametric effects of boiling surface, International Journal of Heat and Mass Transfer Vol. 47 (2004) p. 5033-5044. 